\title{
Loss Analysis Due to Influence of Harmonics in a Distribution System
}

\author{
R. M. Soares, M. E. Oliveira, M. A. A. Freitas, G. P. Viajante and E. N. Chaves \\ Núcleo de Pesquisas em Sistemas de Energia - NUPSE \\ IFG, Instituto Federal de Goiás \\ Campus of Itumbiara - Furnas, 55 Itumbiara (Brazil) \\ Phone/Fax number:+55 64 21035600, e-mail: renanmoreirasoares@gmail.com, marcelo.oliveira@ifg.edu.br
}

\begin{abstract}
The electrical system is subject to rules to guarantee a standard, where several factors can reduce its quality. This can lead to undesirable consequences, such as increased electrical losses in the distribution. As the technology advances and the constant presence of non-linear loads, the electrical network is subject to harmonic distortions that increase the effective value of the current, resulting in inconvenient effects, such as increased losses. In another words, a bigger fraction of the energy is lost by Joule effect and a smaller fraction came to the final consumers. In Brazil, the regulatory agency, in its recommendations, does not consider the effect of harmonic components, obtaining lower results for losses. So, to analyze the influence of these distortions on the operation of a distribution network, simulations were done with the test system LVTestCaseNorthAmerican, with 390 buses. Three distinct climatic cases were analysed, each with a load shape generated from fuzzy logic, all considering the presence of non-linear loads. The simulations were made in OpenDSS, and the losses demonstrated for the three situations. Finally, the importance of considering these distortions in the calculation of losses is discussed.
\end{abstract}

Key words. distribution system, fuzzy, harmonics, OpenDSS, technical losses.

\section{Introduction}

The electrical system is divided, basically, into three major groups: generation, transmission and distribution. Generation is responsible for transforming any type of energy into electrical energy, whether of hydraulic, nuclear or other origins. Whereas transmission is responsible for transporting electricity from generation to those accountable for delivery to consumers, job of the distribution.

In transmission, HV (high voltage) level (above 69kV) are practiced, which, in distribution substations, are transformed to medium voltage (MV) (between $1 \mathrm{kV}$ and $69 \mathrm{kV}$ ) and low voltage (LV) levels. In Brazil, the LV level depends of the location and the concessionaire that manages the network. Most of the LV values is 220/127 V or $380 / 220 \mathrm{~V}$.

In Brazil, generation, transmission and distribution are regulated by the National Electric Energy Agency (in Portuguese: Agência Nacional de Energia Elétrica $A N E E L)$. The Agency set rules and procedures to guarantee a standard in the system, whether to guarantee uniformity in the operation, expansion and quality of energy. For distribution, specifically, ANEEL makes avaliable the Electricity Distribution Procedures in the National Electric System (in Portuguese: Procedimentos de Distribuição de Energia Elétrica - PRODIST). These documents standardize the technical activities related to the operation of the distribution systems. The PRODIST is divided into modules, each one dealing with a specific subject. Module 7 [1] deals with the calculation of distribution losses.

The difference between the electrical energy generated and the energy delivered is characterized as electrical losses. In the distribution system, similarly, losses are defined as the difference between energy received by the distribution system and the energy delivered to consumers. As discussed previously, PRODIST's Module 7 deals with the calculation of distribution losses (technical or non-technical). However, this calculation is performed using only the fundamental frequency of the system, disregarding the higher order frequencies, called harmonics. These frequencies occur in different types of loads connected to the system, and each load has a different characterization of harmonics.

Based on this, this paper investigates the behavior of losses when non-linear loads and consequently harmonics are present in a distribution system. A test system IEEE with 390 buses was considered, changing its operation mainly to $380 / 220 \mathrm{~V}$, in order to better represent the local reality. In addition, load curves were obtained for three different cases according to the relation of energy consumption and climactic conditions, using fuzzy logic. The first case analyzed deal with losses in climatic conditions of cold days, calculating for each hour of the day the amount of power lost by the system. The same is repeated for the other two cases: hot days and mild days. Finally, using the software OpenDSS and its daily and harmonic power flow calculation modes, the losses for the system in each case are analyzed, showing an impact of the presence of harmonics in the distribution system.

\section{Harmonics}

A challenge for electricity utilities is to delivery energy with voltage and current waveforms purely sinusoidal to industrial consumers, maintaining constant frequency and amplitude, within the standards required by ANEEL. However, the waveforms delivered are distorted due to 
harmonic sources in the electrical system. Fig. 1 shows an example of a distorted signal and the signals that compose it.
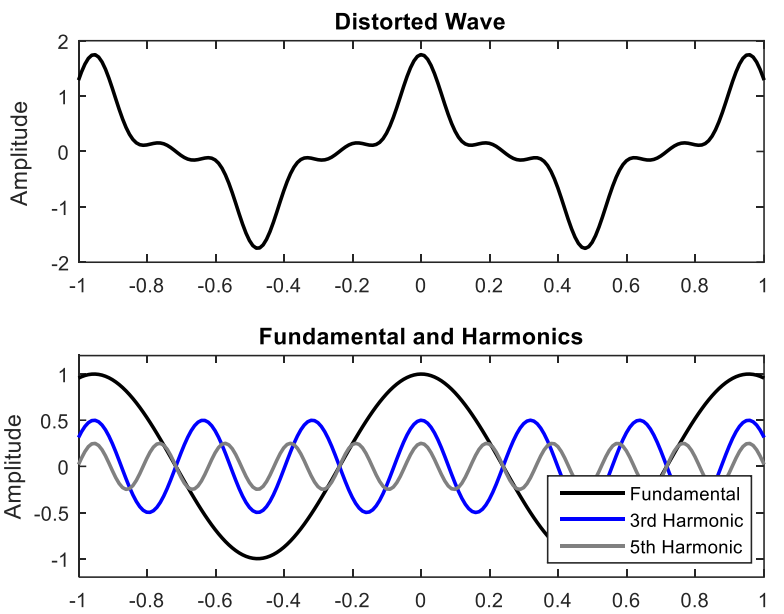

Fig. 1. Signal with deformation and derived signals that compose it, with frequencies of 60,180 and $300 \mathrm{~Hz}$, respectively.

The first waveform is called fundamental, while the others are called harmonic waves. In the Brazilian electrical system, for example, the fundamental frequency is $60 \mathrm{~Hz}$ and the multiplies of this are harmonics, which makes the distorted signal. In a system, there are several sources of harmonics that have different magnitudes and phases angles of the harmonic waves, a characteristic described as harmonic spectrum.

\section{A. Non-linear Loads}

Harmonic distortions arise, mainly, due to loads that don't follow Ohm's law. The currents vary non-linearly with the applied voltage. Computers and smartphones, for example, use switching sources that control the voltage in the load, opening and closing the circuit. This process leads to the generation of harmonics, mainly third and fifth orders, as presented in [2], where a study was carried out to visualize the waveforms and harmonic content of the current in household appliances. As well as motors, large or small, such as fans, also studied in [2]. In addition, another source of harmonics in the power grid are photovoltaic sources and inverters, with significant third and fifth order harmonics.

In transformers, when operating with low or empty current, the magnetization current predominates, having third order harmonic content [3], especially during the night, when there is a low load and high voltages.

The presence of these charges results in an electrical system with distorted conditions, and these effects directly affect it, either in distribution or in equipment. Furthermore, the presence of harmonics is more important that reactives when dealing with non-linear loads. [4]

\section{B. Harmonic effects}

The insertion of harmonics in the electrical system causes a change in the voltage level, distortion of the current form and overheating of transformers. In addition, there is a reduction in the useful life of equipment and an increase in its maintenance.
In rotating machines, the presence of distortions increases losses in iron and copper, consequently increasing heating and affecting efficiency. This heating can affect the coils, due to skin effect, where with increasing frequency the current tends to circulate on the conductor's surface.

As presented in [3], the presence of harmonics components increases the effective value of the current causing problems to the equipment of an electrical network. In addition, his work highlights the effect of these disturbances on the increase in energy losses in distribution and transmission, with a detailed look at losses in conductors also due to the skin effect.

\section{Losses in Distribution Systems}

Losses in distribution systems are divided into two major groups: technical and non-technical losses. Technical losses are due to the energy distribution process, where losses occur in transportation, transformations and due to physical effects. Non-technical losses are defined as the difference between total losses and technical losses. These occur due to measurement errors, energy theft and fraud, that is, they are not related to the technical process of distribution. According to ANEEL [5], Brazil's losses in 2019 represented $14.1 \%$ of the consumer market, $7.5 \%$ due to technical losses.

\section{A. Joule Losses}

In elements with resistive characteristics, such as distribution lines, the passage of current leads to the dissipation of energy in the form of heat, known as the Joule effect. For the presence of harmonic components, this effect can be described by:

$$
P=\sum_{h=1}^{\infty} R I_{h}^{2}=P_{1}+\sum_{h=2}^{\infty} P_{h}
$$

The index 1 of $\mathrm{h}$ indicates the fundamental frequency, while other indicate its multiplies. In such a way, the Joule losses are calculated from the sum of the losses due to the fundamental current and the losses due to each harmonic. The mathematical procedures on this subject are presented in detail in [3]. Note that considering $\mathrm{R}$ constant is a rough approximation.

\section{B. Losses in Transformers}

Losses in transformers occur in their windings due to the Joule effect and in the core, known as hysteresis losses. The hysteresis losses occur due to the saturation of the ferromagnetic material and losses due to eddy currents, also known as Foucault losses. As shown in [6], the losses in the core and in the winding of the transformers increase when feeding non-linear loads. In this work, also shows that the presence of harmonics decreases the capacity of active power, among other effects.

The losses that occur in this equipment are inevitable, therefore, they are included in the portion of technical losses in the distribution, as they occur due to the operation of the transformer. 


\section{Calculation of losses suggested by ANEEL}

PRODIST's Module 7 describes procedures for calculation energy losses in MV and LV systems. For the calculation, three cases are considered: working days, weekends and holidays. In addition, a load curve of the type that represent it must be assigned to each consumer unit. Losses are calculated using the power flow method described in Module 7, obtaining technical and nontechnical losses until it meets the established stopping criterion. Further details on the calculation procedure suggested by ANEEL can be found in [1]. However, the recommended calculation does not include the effects of non-linear and consequently harmonic loads.

\section{System Characterization}

The system used as the object of study was the IEEE's LVTestCaseNorthAmerican model, which presents a model of American LV, present in the examples of OpenDSS, because these are more common and accessible then the Brazilians. It was modified in order to contain the voltages of the Brazilian electrical system. In addition, other modifications and inclusions were made, as shown in sequence.

\section{A. Load shapes}

The load shapes were obtained by reproducing the procedures shown in [7] using the MATLAB® tool for fuzzy set specified in [8], considering some approximations. In [7], load shapes were obtained for three different climatic cases: mild days, cold/ very cold days and hot/ very hot days, based on residential occupation throughout the day.

Table I. - Fuzzy Rules: cold and mild/hot days

\begin{tabular}{|c|c|c|c|}
\hline Day Period & Residential & Cold & Mild / Hot \\
\hline Sleep Period & High 1 & Low & Low \\
\hline Sleep Period & Average 2 & Low & Very Low \\
\hline Breakfast & High 1 & Low & Low \\
\hline Breakfast & Low 1 & High & Low \\
\hline Breakfast & Average 1 & Average & Low \\
\hline Work Period & High 1 & Average & Average \\
\hline Work Period & Low 1 & Very High & Very High \\
\hline Lunch & Low 1 & High & Average \\
\hline Lunch & Average 1 & Average & Average \\
\hline Lunch & Low 2 & Very High & - \\
\hline Lunch & Low 1 & - & High \\
\hline Work Period & Low 1 & Very High & Very High \\
\hline Work Period & Low 2 & High & Very High \\
\hline Dinner & High 2 & Low & Average \\
\hline Dinner & High 2 & Average & - \\
\hline Dinner & Average 2 & Low & Average \\
\hline Rest & High 2 & Average & Average \\
\hline Rest & High 3 & Very Low & Low \\
\hline Sleep Period & Average 1 & - & High \\
\hline Sleep Period & High 3 & Very Low & - \\
\hline Sleep Period & High 3 & Low & - \\
\hline Sleep Period & High 2 & Very Low & \\
\hline
\end{tabular}

The curves obtained represent an ideal situation for residential loads. Based on these works [7][8], in addition to the reproduction of the residential curves, two commercial load curves were constructed using fuzzy logic: cold days (in Brazil, about $18^{\circ} \mathrm{C}$ ) and mild/ hot days (about $30^{\circ} \mathrm{C}$ ).

For commercial cases, the rules used are presented in Table I. The rules were developed using the opposite premise: if residences have a high occupancy, for example, this may imply commerce with low occupancy, in such a way, low consumption. More details and rules for residential cases can be found in the reference work [7].

Finally, the commercial load shapes obtained using this method (Fig.2) were compared with curves in [9] to ensure that they represent reality satisfactorily.

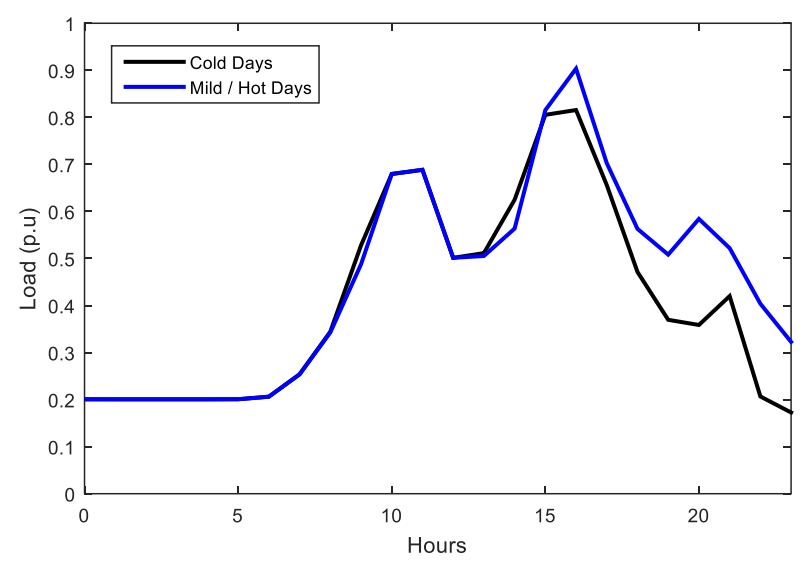

Fig. 2. Commercial load curves raised from fuzzy logic.

\section{B. Harmonic Spectrum}

The system used has 624 loads, and the load shapes and spectrum were distributed, in order, as shown in Table II. The non-linear loads were modeled as current harmonic sources, being a rough approximation. To operate in harmonic mode, each load received a spectrum file containing magnitude (in percent) and angle (in degrees) information for each harmonic order, as shown in Table III [10][11]. If it's not inserted in any load, the software defines a standard spectrum for it.

In addition, three photovoltaic systems were inserted, totaling $7 \mathrm{kVA}$, having a load shape as shown in [11], representing its irradiance, and peak power curves by temperature and efficiency.

Table II. - Distribution of Loads Parameters

\begin{tabular}{|c|c|c|}
\hline Quantity & Load shape & Spectrum \\
\hline 74 & Commercial & Commercial \\
\hline 75 & Residential & Average \\
\hline 60 & Commercial & - \\
\hline 90 & Commercial & Commercial \\
\hline 80 & Residential & Computer \\
\hline 125 & Residential & Low \\
\hline 15 & Residential & - \\
\hline 15 & Residential & Stereo \\
\hline 90 & Public & Lamp \\
\hline
\end{tabular}


Table III. - Harmonic Spectrum

\begin{tabular}{|c|c|c|c|c|c|c|c|c|c|}
\hline Order & 3 & 5 & 7 & 9 & 11 & 13 & 15 & 17 & 19 \\
\hline \multicolumn{10}{|c|}{ Average Residential } \\
\hline$\%$ Mag & 46,4 & 32 & 17,9 & 7,07 & 2,3 & 6,4 & 5,1 & 1,33 & 2,0 \\
\hline Angle & -162 & 16,5 & 21,9 & 22,7 & 87,3 & 121,3 & 119 & 117 & 76,9 \\
\hline \multicolumn{10}{|c|}{ Low Residential } \\
\hline$\%$ Mag & 30,2 & 21,3 & 16,4 & 10,6 & 3,0 & 6,6 & 4,8 & 0,46 & 2,4 \\
\hline Angle & -169 & 16 & -159 & 22,7 & 106 & -122 & 58,4 & -124 & -103 \\
\hline \multicolumn{10}{|c|}{ Commercial } \\
\hline$\%$ Mag & 16,8 & 7,5 & 2,2 & 1,4 & 0,5 & 1,07 & 0,8 & 0,6 & 1,1 \\
\hline Angle & -156 & 9,5 & -161 & $-5,3$ & 32,3 & -140 & 30,2 & 7,39 & -160 \\
\hline \multicolumn{10}{|c|}{ Computer } \\
\hline$\%$ Mag & 27 & 11 & 5 & 2 & 1,7 & 1,3 & 1 & - & - \\
\hline Angle & - & - & - & - & - & - & - & - & - \\
\hline \multicolumn{10}{|c|}{ TV } \\
\hline$\% \mathrm{Mag}$ & 82,3 & 54,8 & 25,2 & 3,4 & 10,5 & 11,8 & 6,3 & 0,84 & 0,38 \\
\hline Angle & 175 & $-7,6$ & 173 & 43,1 & -33 & 146 & -42 & $-1,1$ & 61,7 \\
\hline \multicolumn{10}{|c|}{ Stereo System } \\
\hline$\% \mathrm{Mag}$ & 37,4 & 17,3 & 6,0 & 5,9 & 2,0 & 2,6 & 1,0 & 1,2 & 0,7 \\
\hline Angle & -179 & -48 & -18 & 133 & -128 & $-46,5$ & 76,6 & 137 & -109 \\
\hline \multicolumn{10}{|c|}{ Lamp } \\
\hline$\%$ Mag & 66,0 & 42,4 & 40,1 & 28,3 & 19,6 & 15,3 & 10,9 & 10,2 & 10,7 \\
\hline Angle & -71 & -144 & 135 & 47,0 & $-21,4$ & $-91,6$ & -149 & 150 & 86,9 \\
\hline \multicolumn{10}{|c|}{ Inverter } \\
\hline$\% \mathrm{Mag}$ & 1,16 & 1,41 & 0,22 & 0,04 & 0,16 & 0,23 & 0,11 & - & - \\
\hline Angle & - & - & - & - & - & - & - & - & - \\
\hline
\end{tabular}

\section{Case Study}

The study was based on what was developed in [3] and [12] regarding the increase in technical losses due to harmonics. The considerations on photovoltaic systems found in [11] and [13] were added, expanding the calculations for odd harmonic spectrum of up to nineteenth order and performing them for a LV system with 390 buses.

With the data collected, a routine was developed in MATLAB $®$ integrated with OpenDSS in such a way that the power flow was calculated for three cases: cold day (1), mild day (2) and hot day (3). For each of these cases, the calculation was restarted, and the respective load shape obtained by fuzzy logic were inserted.

In addition, for each case, using the daily mode, the power flow was performed hourly. For each hour, however, nine other simulations were performed in harmonic mode, each for a harmonic frequency. It is necessary to highlight that before of the realization of each harmonic flow, it was necessary to perform the fundamental power flow corresponding to the calculated hour.

Using the export summary command at the end of the fundamental flow and harmonics, for each hour and case, three tables were recorded, given as time of day and their respective active power losses for each solution, fundamental and harmonics. In order to confront the data, still in MATLAB $®$, at the end of each solution the systems losses were stored in matrix form, through the losses command.

\section{Losses Analysis}

From the simulations performed, active losses were obtained for each case, considering each hour and each harmonic. For the fundamental frequency of $60 \mathrm{~Hz}$, daily energy losses of up to $2.9 \mathrm{MWh}$ were obtained, as shown in Table IV. The losses for each frequency were separated, to visualize the influence of each one on the losses. Due to the discrepancy in the data orders, Fig. 3-A and 3-B shows the active losses resulting from the harmonic components separated in two graphics, to improve the visualization.

Table IV. - Daily Losses in the System (kWh)

\begin{tabular}{|c|c|c|c|c|}
\hline $\begin{array}{c}\text { Harmonic } \\
\text { Order }\end{array}$ & $\begin{array}{c}\text { Case 1: } \\
\text { Cold Day }\end{array}$ & $\begin{array}{c}\text { Case 2: } \\
\text { Mild Day }\end{array}$ & $\begin{array}{c}\text { Case 3: } \\
\text { Hot Day }\end{array}$ & Mean \\
\hline Fundamental & 2395,94 & 2691,29 & 2901,34 & 2662,86 \\
\hline 3 & 471,05 & 504,51 & 531,64 & 502,4 \\
\hline 5 & 46,93 & 48,17 & 52,63 & 49,24 \\
\hline 7 & 39,08 & 38,88 & 41,74 & 39,9 \\
\hline 9 & 44,85 & 44,33 & 50,74 & 46,64 \\
\hline 11 & 4,42 & 4,43 & 4,51 & 4,45 \\
\hline 13 & 4,36 & 4,39 & 4,74 & 4,5 \\
\hline 15 & 1,39 & 1,43 & 1,51 & 1,44 \\
\hline 17 & 1,53 & 1,55 & 1,56 & 1,54 \\
\hline 19 & 1,77 & 1,86 & 1,91 & 1,85 \\
\hline
\end{tabular}

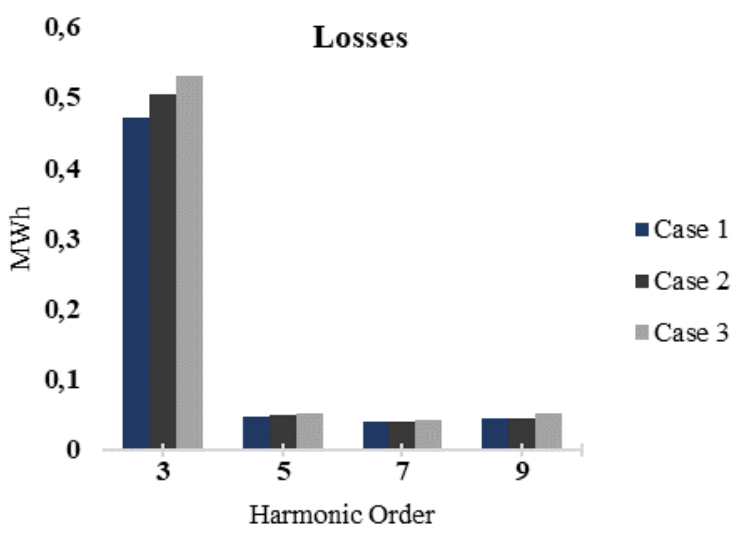

Fig. 3-A. Losses due to harmonics of order 3 to 9 for the three cases: cold, mild and hot, respectively. (MWh)

Losses

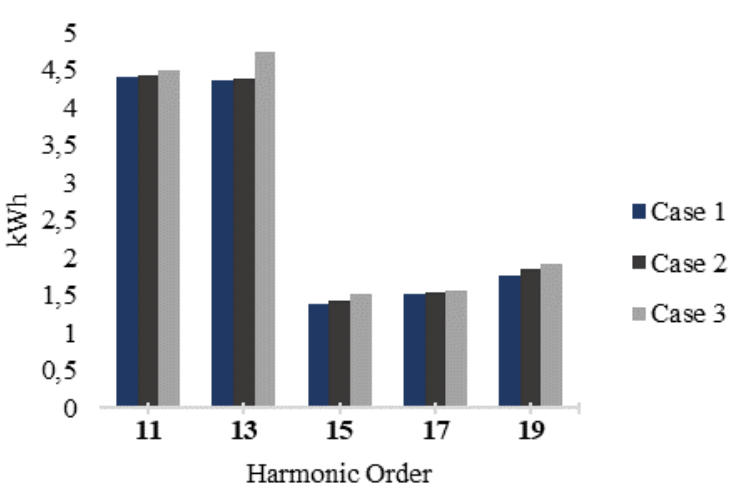

Fig. 3-B. Losses due to harmonics of order 11 to 19 for the three cases: cold, mild and hot, respectively. (kWh) 
As a percentage of total daily losses, losses due to fundamental frequency and their harmonics were expressed in Fig. 4-A. Note that for harmonics above 9 the percentage losses tend to zero.

Fig. 4-B shows a comparison between the mean of losses due to only to the fundamental frequency, as recommended by ANEEL, and the total losses considering the harmonic components.

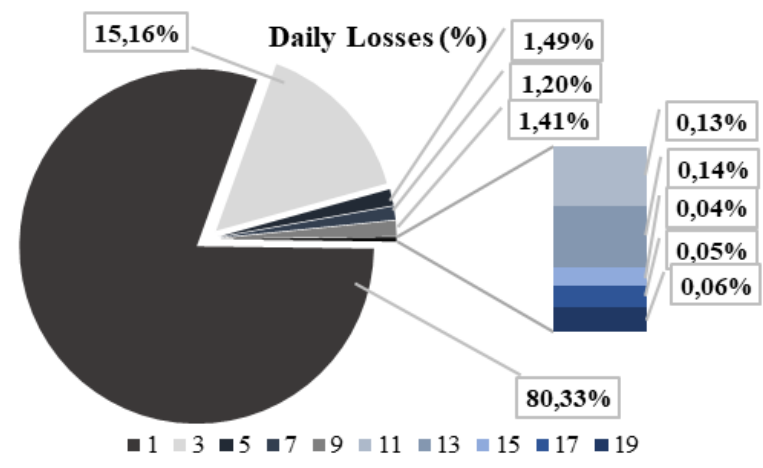

Fig. 4-A. Mean of daily losses displayed in percentage, due to fundamental and harmonics.

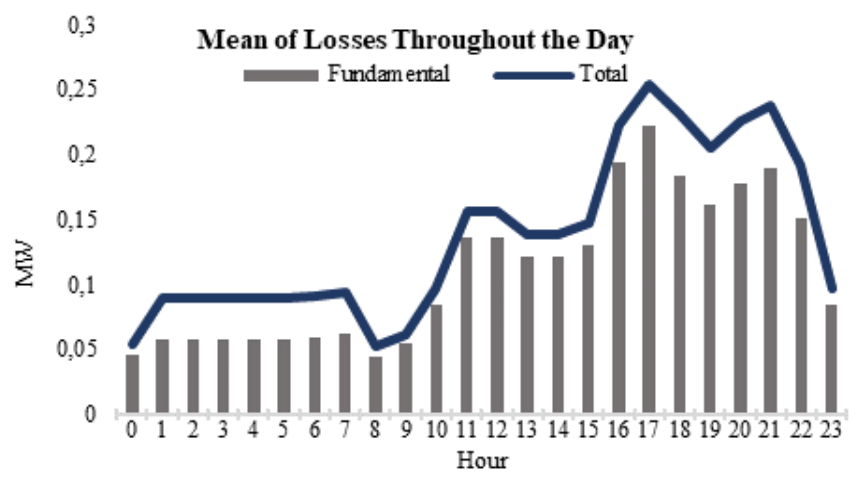

Fig. 4-B. Losses throughout the day for the fundamental frequency and total losses. The values are means of the three cases. (MW)

\section{Conclusion}

In this study, losses due to the influence of harmonic components in a low voltage distribution system were analyzed, using an IEEE model for simulations. The analyzes were performed on three different cases, each with specific load curves obtained by fuzzy logic.

It was observed that the losses obtained in the third case were higher, as expected, since the load shapes used predicted this behavior for hot days. In addition, analyzing the losses hourly, considering the mean between the cases, it was found that the losses are more significant at times when consumption is higher, according to the load curves. From the plotted graphs, it was observed that the third order harmonics are the ones that represent greater losses within this group, as well as it is noticed that the losses of very high orders, in percentage, are irrelevant. It was also verified that the technical losses due to harmonics correspond to about $19.6 \%$ of the total technical losses for this system.

It is noted that the losses obtained are relevant, however, these were hypothetical situations that do not fully correspond to reality, because despite the curves obtained by fuzzy to represent well, the spectrum were randomly distributed for loads already existing in the model.

Finally, it ensures that the calculation of these losses, beyond being necessary, is liable to be recommended by ANEEL. However, the difficulty would be in defining reliable harmonic spectrum for each consumer unit, and a survey should be made of these for precise results.

\section{References}

[1] ANEEL, "Procedimentos de distribuição de energia elétrica no sistema elétrico nacional - PRODIST / Módulo 7 - Cálculo de perdas na distribuição" Rev. 5. (2016), pp. 4-18

[2] G. Dionisio and L. E.S. Spaldin, "Dionisio, G., \& Spalding, L. E. S. (2017). Visualização da forma de onda e conteúdo harmônico da corrente elétrica alternada em eletrodomésticos", Revista Brasileira de Ensino de Física, Vol. 39, São Paulo (2017), pp. 8-13.

[3] L. L. Braz, Quantificação das perdas técnicas da distribuição em condições distorcidas, Uberlândia (2019).

[4] W. Kui, et al. "Investigation of harmonic distortion and losses in distribution systems with non-linear loads." 2008 China International Conferrence on ElectricityDistribution. IEEE, 2008.

[5] ANEEL, "Relatório - Perdas de Energia Elétrica na Distribuição" Edição 01/2019. (2019), pp. 2-4.

[6] L. R. Lisita, Determinação de Perdas, Eficiência e Potência Máxima de Transformadores de Distribuição Alimentando Cargas Não-Lineares, Goiânia (2004).

[7] T. Santos, Determinação de perfil de curva de carga residencial baseado num sistema-fuzzy, Ilha Solteira (2016).

[8] M. Amendola, L. Barros and A. Souza, Manual do uso da teoria dos conjuntos Fuzzy no MATLAB 6.5. FEAGRI \& IMECC/UNICAMP, Campinas (2015).

[9] A. A. Francisquini, Estimação de curvas de carga em pontos de consumo e em transformadores de distribuição, Ilha Solteira (2016), pp. 28.

[10] I. Pires, Caracterização de harmônicos causados por equipamentos eletro-eletrônicos residenciais e comerciais no sistema de distribuição de energia elétrica, Minas Gerais (2016).

[11] L. R. Silva, . Avaliação de perdas na presença de cargas não lineares na rede elétrica utilizando o software OpenDSS, Brasília (2017), pp. 45.

[12] O. Arikan, "Influence of Harmonics on Medium Voltage Distribution System: A Case Study for Residential Area", World Academy of Science, Engineering and Technology, International Journal of Electrical, Computer, Energetic, Electronic and Communication Engineering, v. 9, n. 8. (2015).

[13] F. F. Barros, Avaliação dos Impactos da Inserção de Fontes Fotovoltaicas na Rede Elétrica no Tocante às Grandezas de Qualidade da Energia, Brasília (2016). 